\title{
Rancang bangun penjejak posisi matahari menggunakan kamera dan single board computer
}

\author{
Faisal Wahab* \\ Program Studi Teknik Elektro, Universitas Katolik Parahyangan \\ Jl. Ciumbuleuit No. 94, Bandung 40141, Jawa Barat, Indonesia \\ faisal.wahab@unpar.ac.id
}

\begin{abstract}
ABSTRAK
Energi matahari adalah sumber energi terbesar yang ada di muka bumi ini. Panel surya merupakan sebuah peranti elektronik yang dapat memanfaatkan energi dari sinar matahari untuk dikonversi menjadi energi listrik. Semakin besar permukaan panel surya tersinari cahaya matahari, maka energi listrik yang dihasilkan lebih besar. Makalah ini memaparkan rancang bangun penjejak matahari menggunakan kamera sebagai pendeteksi posisi matahari dengan modul Raspberry pi sebagai kendali untuk pengolahan citra. Pergerakan penjejak posisi matahari ini menggunakan dua aksis, yaitu pitch dan roll. Aktuator yang digunakan untuk mengikuti posisi matahari adalah dua buah motor DC dengan jenis linier aktuator. Hasil dari pengujian menunjukan bahwa kamera dapat mendeteksi titik cahaya menggunakan pengolahan citra pada modul Raspberry pi. Kemudian rangka penjejak sinar matahari berhasil menuju posisi yang diinginkan yaitu pada titik tengah kamera dengan menggerakan dua buah linier aktuator melalui driver motor.
\end{abstract}

Kata kunci: panel surya, penjejak matahari, linier aktuator, kamera, pengolahan citra

\section{ABSTRACT}

Solar energy is the largest source of energy on the earth. The solar panel is a device for converting solar energy into electrical energy. The larger surface of the solar panels exposed to sunlight, the greater electrical energy are produced. This paper describes the design of a sun tracker using a sun detection camera with the Raspberry pi module as control for image processing. The tracking of the sun's position uses two axes, namely pitch and roll. The actuators used to track the position of sunlight are two DC motors with the linear actuator type. The experimental results show that the camera can detect points of light using image processing on the Raspberry pi module. Then the frame of the sunlight tracker succeeds to achieved the desired position, namely at the center point of the camera by moving two linear actuators through the motor driver.

Keywords: solar panels, sun tracker, linear actuator, camera, image processing

\section{PENDAHULUAN}

Energi yang besar dan muncul setiap hari adalah energi matahari. Energi matahari merupakan sumber energi terbarukan yang sangat besar yang ada di permukaan bumi. Mengingat Indonesia merupakan negara khatulistiwa, Indonesia memiliki jam penyinaran matahari yang cukup lama, yaitu hampir 12 jam perhari dan menjadi negara terbesar serapan tenaga surya di ASEAN [1].

Salah satu alat yang digunakan untuk memanfaatkan energi matahari adalah panel surya. Panel surya merupakan peranti elektronik yang dapat mengkonversi energi matahari menjadi energi listrik. Panel surya terbentuk dari kepingan yang memiliki tebal sekitar $3 \mathrm{~mm}$, terdiri dari kutub positif dan negatif, serta terbuat dari irisan bahan semikonduktor. Pemanfaatan panel surya sebagai sumber listrik telah banyak digunakan dan diteliti, diantaranya pada [2]-[4].

Penggunaan panel surya yang terpasang selama ini masih banyak bersifat statis, sehingga panel surya tidak dapat menangkap sinar matahari secara maksimal. Posisi matahari yang setiap detik bergeser dari timur ke barat mengakibatkan panel surya yang bersifat statis tidak semua waktu dapat terkena sinar matahari. Dengan demikian, penggunaan penjejak matahari perlu digunakan agar permukaan panel surya dapat menyerap sinar matahari secara maksimal. Hal ini telah dibuktikan oleh [5] dan [6] bahwa penggunaan panel surya dengan sistem penjejak matahari menghasilkan daya yang lebih besar dibandingkan dengan panel surya yang statis. 
Sistem penjejak matahari biasanya menggunakan sensor-sensor seperti light dependent resistor (LDR) [7] atau photodioda [8] sebagai umpan balik untuk mendeteksi matahari. Namun, tingkat akurasi penggunaan sensor tersebut masuk dalam kategori rendah dan diperlukan teknologi lain yang dapat meningkatkan tingkat akurasi supaya matahari dapat terserap maksimal oleh panel surya. Salah satu teknologi tersebut adalah penerapan teknologi kamera [9]. Penggunaan kamera dinilai lebih akurat dibandingkan dengan penggunaan sensor LDR [10]. Hal ini karena dengan menggunakan kamera, matahari akan terdeteksi dari posisinya dibandingkan dengan menggunakan sensor LDR yang masih membandingkan nilai tertinggi dari sinar matahari. Data dari kamera ini perlu diolah terlebih dahulu supaya dapat digunakan sebagai umpan balik untuk mengetahui posisi matahari. Proses ini disebut dengan pengolahan citra atau biasa disebut dengan image processing. Pengolahan citra ini membutuhkan sebuah perpustakaan (library) untuk mengolah gambar atau video sehingga dapat diambil sebuah informasi dari data tersebut. OpenCV merupakan salah satu perpustakaan untuk pengolahan citra yang banyak digunakan. Pada umumnya, pengolahan citra dari kamera dikirim dan diolah menggunakan personal komputer. Penggunaan perangkat ini, dinilai kurang efisien jika dalam beberapa kondisi tertentu, diantaranya penjejak matahari disimpan pada daerah sulit dijangkau dan membutuhkan konsumsi energi listrik yang cukup besar. Dari penjelasan tersebut, perlu adanya sebuah mini komputer yang dapat digunakan untuk pengolahan citra serta memiliki konsumsi energi yang kecil, seperti Raspberry pi.

Penelitian ini bertujuan untuk merancang dan membangun penjejak matahari menggunakan kamera dan single board computer sebagai pengolahan citra. Penelitian ini berfokus pada pembuatan sistem penjejak matahari dan tidak melakukan analisis tegangan atau arus yang keluar dari panel surya. Hal ini menjadi batasan karena diasumsikan jika posisi matahari tegak lurus dengan permukaan panel surya, maka penyerapan energi matahari oleh panel surya akan maksimal. Sistem ini dirancang menggunakan OpenCV sebagai perangkat lunak pengolah citra dan Raspberry pi sebagai single board computer.

\section{METODE PENELITIAN}

Rancang bangun sistem penjejak matahari ini terdiri dari sistem mekanik, sistem elektrik, dan algoritma pengolahan citra. Gambar 1 merupakan diagram blok sistem penjejak matahari yang dibuat. Penempatan kamera dan panel surya disimpan satu rangka dan sejajar supaya kamera dapat merepresentasikan permukaan panel surya.

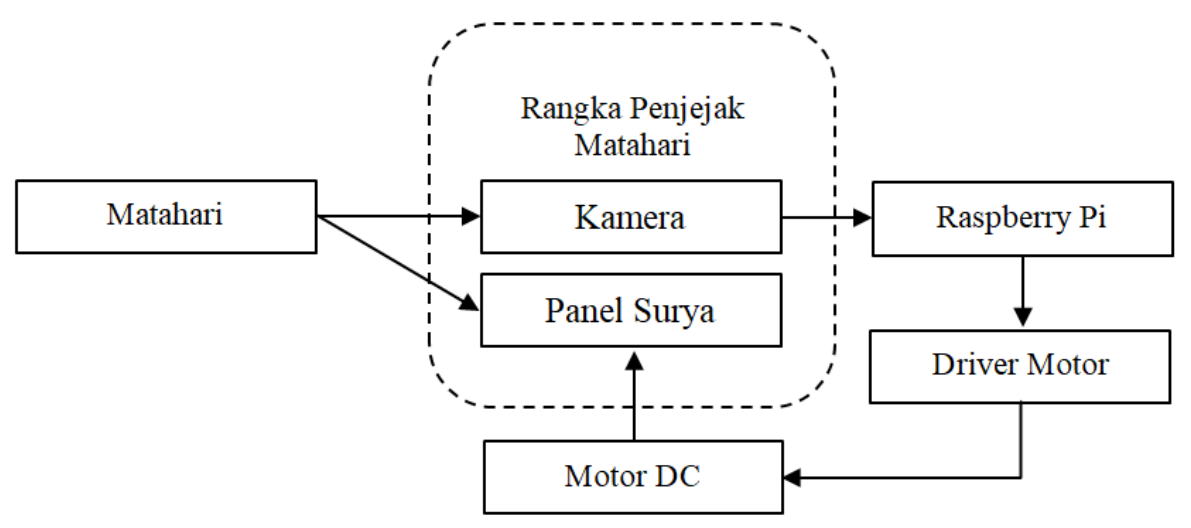

Gambar 1. Diagram blok sistem penjejak matahari

Perancangan penjejak matahari yang dibuat menggunakan dua buah aksis, yaitu putaran sumbu $\mathrm{x}$ (pitch) dan putaran sumbu y (roll). Penggunaan dua aksis ini sesuai dengan posisi matahari yang bergerak dari timur ke barat. Posisi yang ditentukan adalah altitude dan azimuth. Altitude adalah ukuran sudut antara garis cakrawala dengan objek (matahari) menggunakan roll, sedangkan azimuth adalah jarak sudut searah jarum jam menggunakan pitch. Karena menggunakan dua aksis, maka diperlukan sebuah mekanisme agar panel surya dapat bergerak mengikuti posisi matahari. Perancangan yang akan dibuat diilustrasikan pada Gambar 2. 


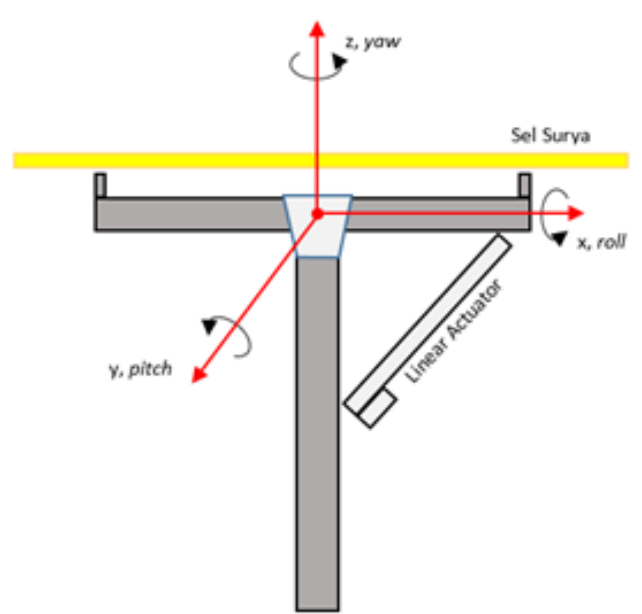

(a)

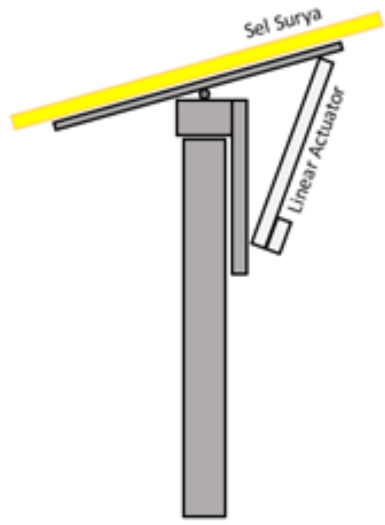

(b)

Gambar 2. Rancangan mekanik panel surya: (a) tampak samping (sumbu y), (b) tampak belakang (sumbu x)

Rancangan ini menggunakan dua buah penggerak berupa linier aktuator yang digunakan untuk menggerakan sudut pitch dan roll yang disimpan pada batang penyangga. Pada Gambar 2 (a), linier aktuator akan memutarkan sumbu y atau pitch, sedangkan Gambar 2 (b) akan memutarkan sumbu x atau roll.

\subsection{Perancangan Sistem Elektrik}

Pada bagian ini akan dijelaskan diagram blok pada Gambar 3 dan komponen yang digunakan pada sistem elektrik.

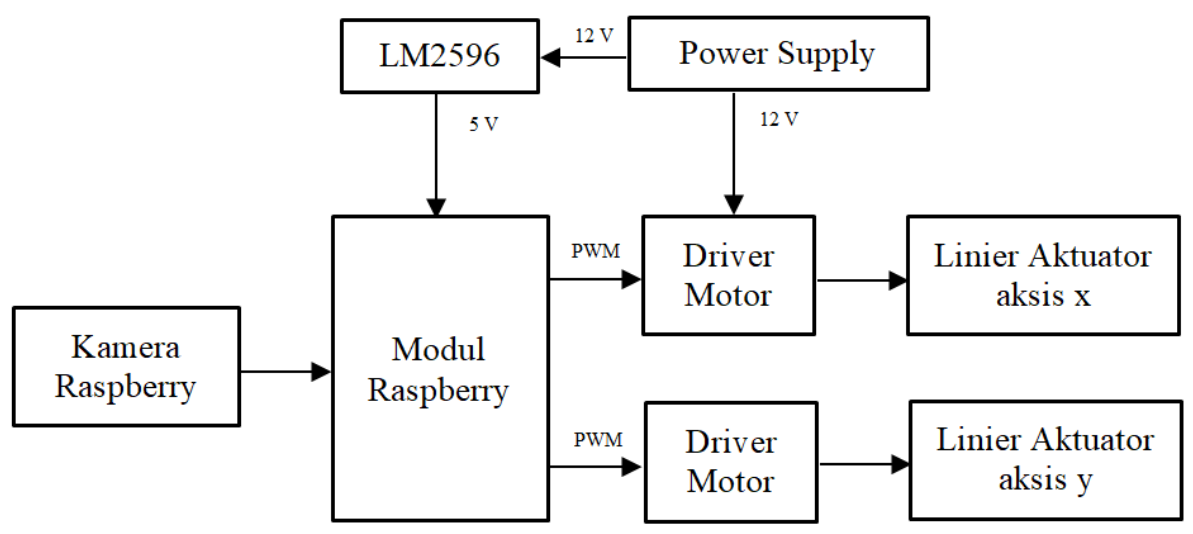

Gambar 3. Diagram blok sistem elektrik

Berikut ini penjelasan komponen sistem elektrik yang digunakan dalam penelitian ini:

1. Kamera Raspberry pi berfungsi untuk menangkap gambar dari lingkungan.

2. Raspberry pi digunakan untuk pengendali dan pengolahan citra. Sistem operasi yang digunakan pada penelitian kali ini adalah Raspbian dan library yang digunakan untuk pengolahan citra adalah OpenCV.

3. Driver motor BTS7960 digunakan untuk mengendalikan arah putaran dan kecepatan motor linier aktuator dari modul Raspberry pi.

4. Linier aktuator berfungsi sebagai penggerak untuk mengatur modul panel surya supaya tegak lurus dengan posisi matahari. Linier aktuator yang digunakan memiliki panjang 18 inch dan dapat menahan beban sampai dengan $100 \mathrm{Kg}$.

5. Power supply digunakan sebagai catu daya utama dengan spesifikasi 12V/10A.

6. LM2596 digunakan untuk menurunkan tegangan dari 12V menjadi 5V. Tegangan 5V diperlukan untuk mengaktifkan Raspberry pi. 


\subsection{Sistem Operasi dan Pemrosesan Data}

Untuk dapat menggunakan modul Raspberry pi, diperlukan sebuah sistem operasi supaya modul tersebut dapat digunakan. Pada umumnya sistem operasi yang digunakan adalah Raspbian. Raspbian merupakan sistem operasi berbasis Linux resmi yang dikeluarkan oleh Raspberry pi. Sistem operasi Raspbian didapatkan dari new out of the box software (NOOBS) yang merupakan sistem operasi manager yang dapat memudahkan untuk download, install, dan setting Raspberry pi.

Raspbian belum memiliki library untuk pengolahan citra, maka perlu adanya sebuah library tambahan untuk memproses sebuah gambar yang diambil dari sebuah kamera. Hasil dari gambar tersebut diolah dan selanjutnya menjadi referensi pergerakan dari penjejak matahari. Library yang digunakan untuk pengolahan citra adalah OpenCV. OpenCV adalah singkatan dari open source computer vision. OpenCV merupakan sebuah library bebas (open source) yang digunakan untuk operasi computer vision dan machine learning. Pada penelitian ini OpenCV diterapkan menggunakan bahasan pemrograman $\mathrm{C}++$ dan diprogram menggunakan modul Raspberry pi.

Pada penelitian ini terdapat beberapa tahapan pengolahan citra dari mendeteksi posisi matahari sampai dengan memberikan input pada linier aktuator sebagai berikut.

1. Tahapan yang pertama filter warna dari gambar yang ditangkap, yaitu adalah merubah warna red, green, dan blue (RGB) menjadi hue, saturation, value (HSV) dengan tujuan untuk pengenalan warna yang lebih sederhana untuk pemahaman manusia. Hue merepresentasikan warna sebenarnya untuk menentukan kehijauan atau kemerahan dari warna tersebut. Saturation merepresentasikan kemurnian atau kekuatan warna. Value merepresentasikan kecerahan dari sebuah warna dengan kisaran 0-100\%. Gambar 4 menunjukan hasil konversi dari RGB menjadi HSV.

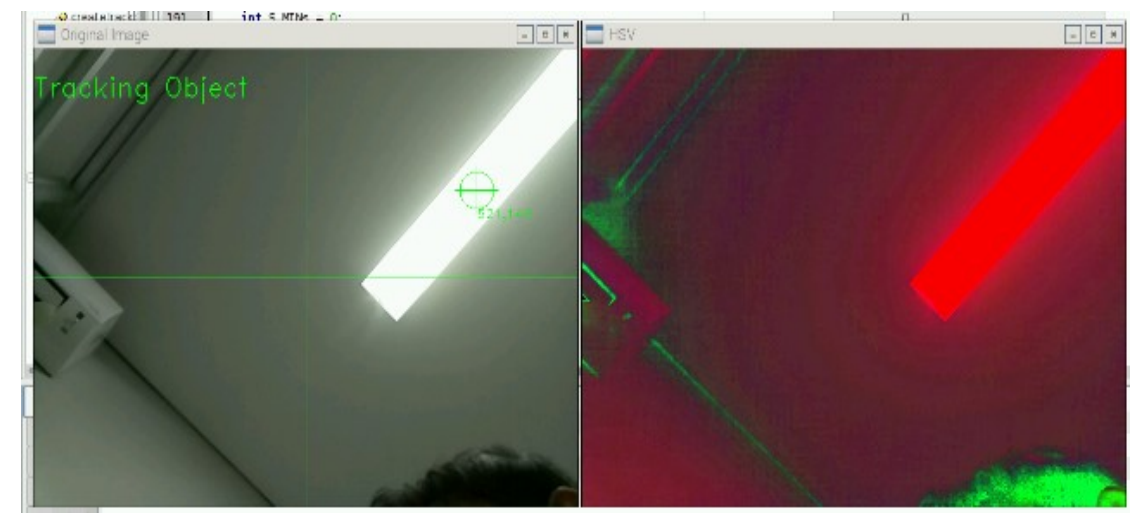

Gambar 4. Hasil tampilan RGB dari kamera asli (kiri) dikonversi menjadi HSV (kanan)

2. Tahap kedua adalah memfilter warna HSV menjadi threshold image dengan mengatur intensitas warna sesuai dengan warna yang diinginkan. Terlihat ilustrasi pada Gambar 5 yang menunjukkan bahwa warna titik cahaya dikonversi menjadi warna putih dan warna lain yang diambil menjadi warna hitam. Tujuan dari tahapan ini adalah menentukan warna mana yang akan digunakan sebagai referensi untuk proses penentukan titik posisi.
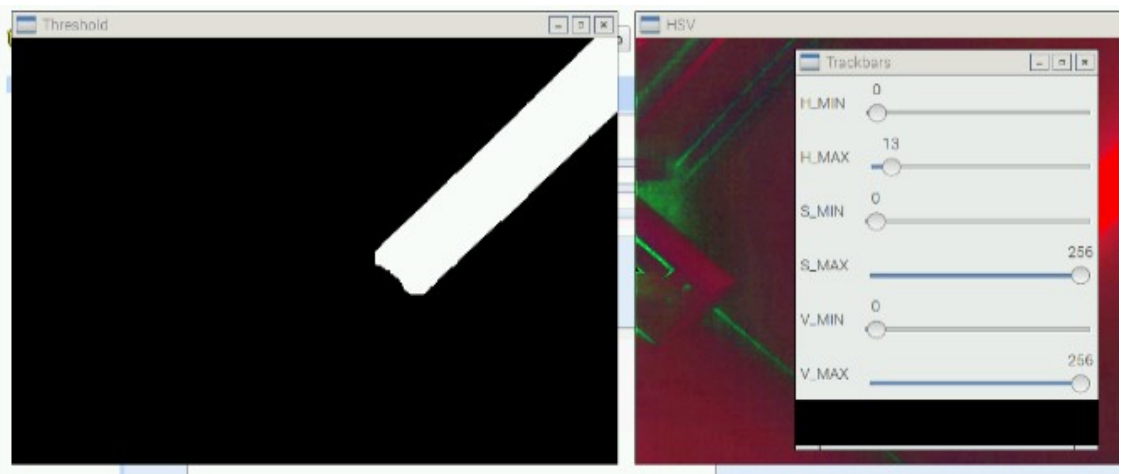

Gambar 5. Hasil konversi ke threshold (kiri) dan tampilan pengaturan threshold (kanan) 
3. Tahap ketiga adalah mencari kontur dan mencari momen untuk menentukan titik tengah dari hasil threshold. Gambar 6 menunjukan hasil dari tahap ketiga ditandai dengan warna hijau bulat. Warna hijau ini menandakan titik tengah dari cahaya atau warna yang telah melewati HSV dan threshold.

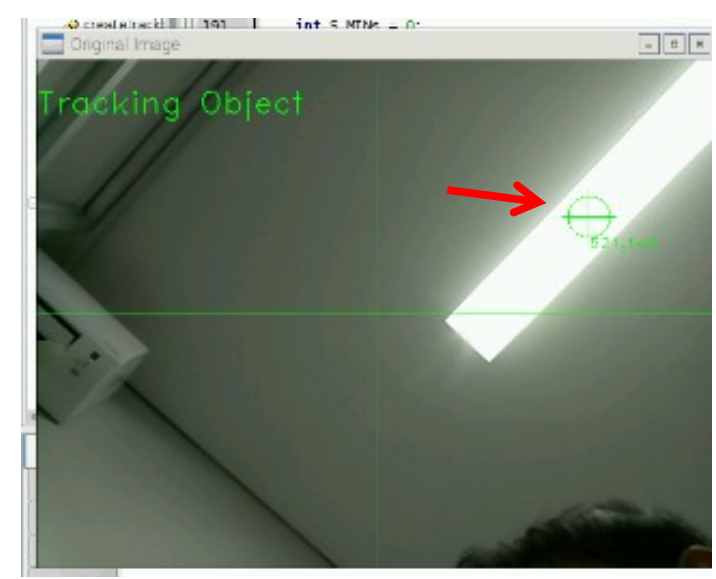

\section{Gambar 6. Tampilan seteleh ditentukan kontur dan momen}

\subsection{Algoritma Sistem Penjejak Matahari}

Gambar 7 menunjukan bagan alir sistem dari sistem penjejak matahari. Pendeteksian posisi cahaya pada kamera dibagi dalam dua aksis, yaitu $\mathrm{x}$ dan y dengan ukuran piksel layar yang digunakan adalah 640 x 480 . Aksis x berada pada 0-640 dan aksis y berada pada 0-480. Oleh karena itu, titik tengah kamera berapa pada posisi $\mathrm{x}=320$ dan $\mathrm{y}=240$ yang ditunjukan pada Gambar 8 dan terbagi ke dalam empat kuadran, yaitu kuadran 1, kuadran 2, kuadran 3, dan kuadran 4.

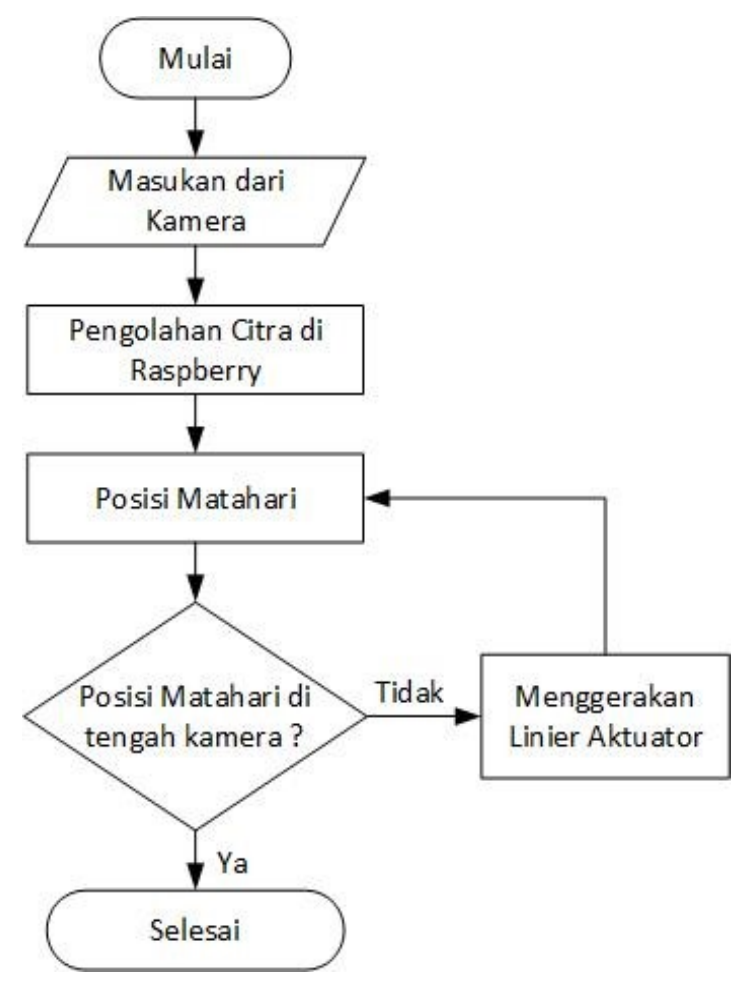

Gambar 7. Bagan alir sistem penjejak matahari

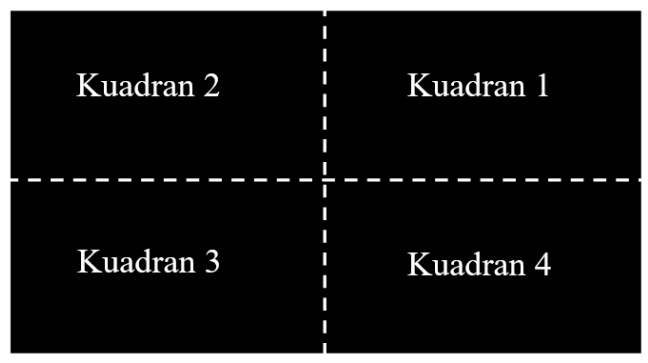

Gambar 8. Pembagian kuadran pada kamera

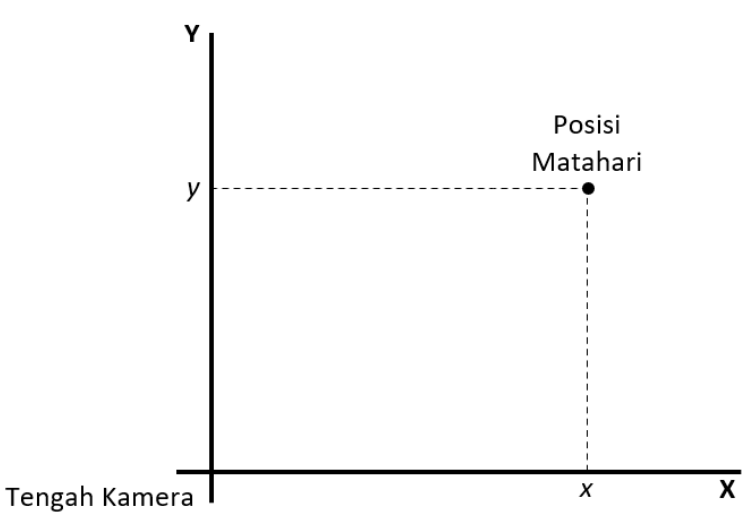

Gambar 9. Contoh posisi matahari kuadran 1

Jika, posisi cahaya berada pada kuadran 1, maka selanjutnya adalah Raspberry Pi menggerakan motor aksis $\mathrm{x}$ dan aksis y supaya posisi cahaya tersebut berada pada posisi tengah kamera. Setelah posisi matahari berada pada tengah kamera, maka motor aksis $\mathrm{x}$ dan y berhenti. Pada Gambar 10 berikut adalah ilustrasi pendeteksian dan penggerakan motor $\mathrm{x}$ dan $\mathrm{y}$. 
Berikut adalah list program yang digunakan untuk menggerakan aksis $\mathrm{x}$ dan $\mathrm{y}$. Pin keluaran dari Raspberry pi untuk menggerakan aksis $\mathrm{x}$ adalah pin 15 dan pin 16, sedangkan untuk menggerakan aksis y digunakan pin 1 dan pin 4. Kondisi HIGH menandakan bahwa logika keluaran bernilai satu atau $5 \mathrm{~V}$, sedangkan LOW menandakan bahwa logika keluaran bernilai nol atau $0 \mathrm{~V}$.

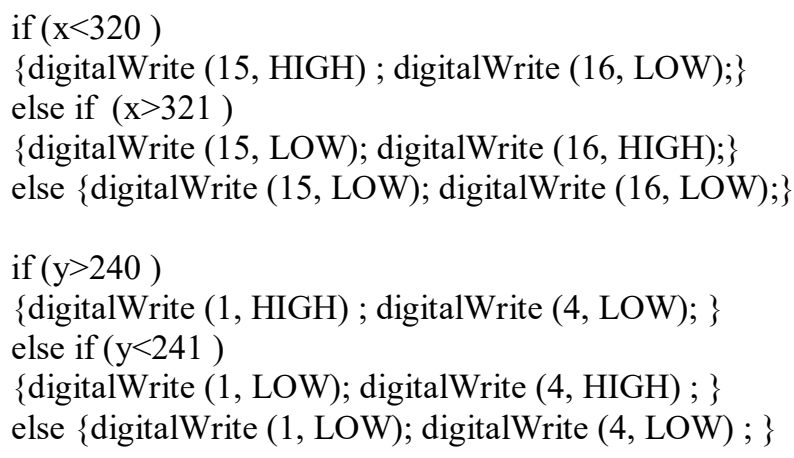

Jika posisi cahaya matahari berada pada $\mathrm{x}<320$, maka motor $\mathrm{x}$ akan bergerak CW (clockwise) dan sebaliknya jika posisi cahaya $\mathrm{x}>321$ maka motor $\mathrm{x}$ bergerak CCW (counter clockwise). Begitu juga jika posisi cahaya $\mathrm{y}<240$ motor y akan bergerak CW (clockwise) dan posisi cahaya y $>241$ maka motor $\mathrm{y}$ bergerak CCW (counter clockwise). Namun jika posisi matahari berada pada posisi $\mathrm{x}=240$ dan $\mathrm{y}=320$, maka kedua motor tersebut akan berhenti yang menunjukan posisi matahari berada pada tengah kamera.

\section{HASIL DAN PEMBAHASAN}

Bagian ini berisi hasil dan pembahasan dari yang diperoleh dari hasil perancangan dan pengujian. Hasil dan pembahasan meliputi realisasi perangkat keras serta pengujian pendeteksian posisi matahari berbasis kamera.

\subsection{Realisasi Perangkat Keras}

Setelah sistem mekanik penjejak matahari dirancang, tahap selanjutnya adalah proses pembuatan. Spesifikasi dari rangka penjejak posisi matahari memiliki panjang 1,6 meter, lebar 2 meter, dan tinggi 1,6 meter. Bahan yang digunakan untuk membuat rangka adalah aluminium hollow. Bahan alumunium ini digunakan karena cukup kuat menahan beban panel surya dan juga tahan karat sehingga dapat digunakan dalam waktu yang panjang. Gambar 10 menunjukan hasil pembuatan rangka penjejak matahari. Gambar 10 (a) menunjukan pemasangan linier aktuator untuk menggerakan aksis x, Gambar 10 (b) menunjukan pemasangan linier aktuator untuk menggerakan aksis y, dan Gambar 10 (c) menunjukan panel surya yang digunakan.

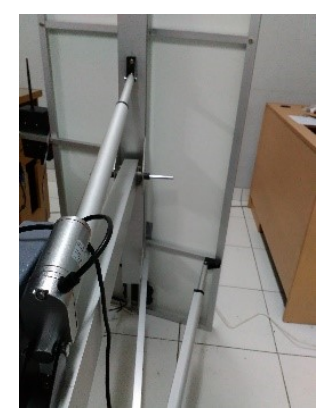

(a)

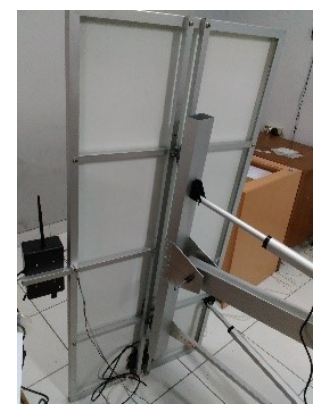

(b)

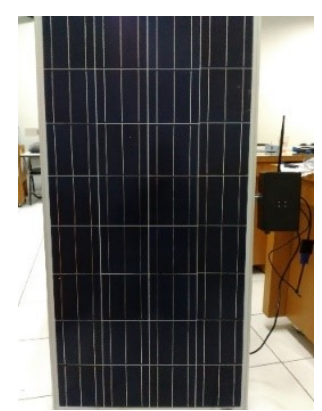

(c)

Gambar 10. Rangka penjejak matahari: (a) penggerak aksis $x$, (b) penggerak aksis $y$, dan (c) panel surya yang digunakan

Selain sistem mekanik, sistem elektrik juga direalisasikan ke dalam perangkat keras seperti pada Gambar 11. Gambar 11 (a) memperlihatkan modul elektrik yang digunakan yang disimpan pada batang utama rangka, Gambar 11 (b) kamera disimpan sejajar dengan permukaan panel surya, dan Gambar (c) tampilan hasil pengolahan citra pada layar monitor sebagai pemantau kamera. 


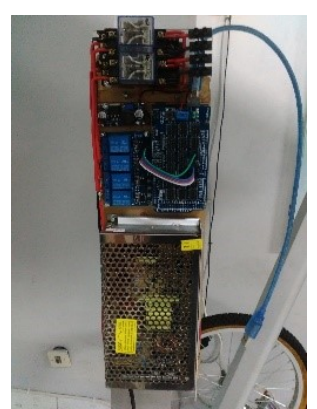

(a)

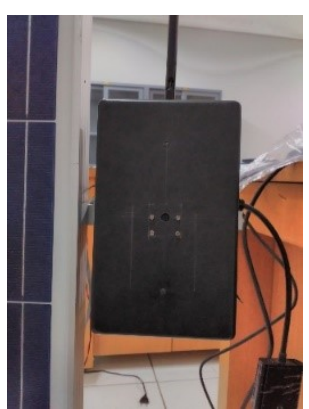

(b)

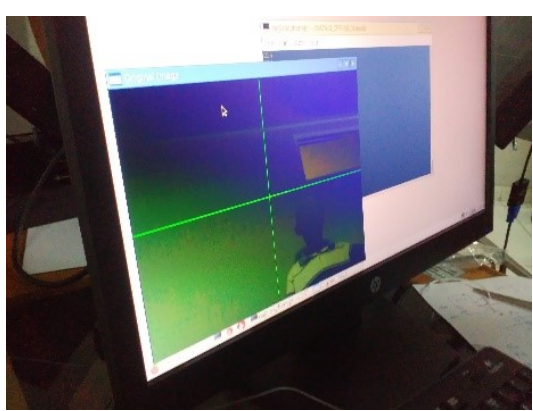

(c)

Gambar 11. Realisasi perangkat elektrik: (a) sistem elektrik, (b) penempatan kamera, dan (c) tampilan pemrosesan

\subsection{Pengujian Pendeteksian dan Penjejak Titik Cahaya}

Pendeksian titik cahaya dilakukan menggunakan sebuah senter yang disorotkan langsung ke kamera. Dari hasil pengujian didapatkan nilai HSV adalah sebagai berikut HMIN $=0, \mathrm{H} \_\mathrm{MAX}=13$, S_MIN $=0$, S_MAX $=256, \mathrm{~V} \_$MIN $=0, \mathrm{~V} \_$MAX $=256$. Nilai HSV tersebut dapat diatur sesuai dengan intensitas cahaya yang dideteksi, termasuk cahaya matahari.

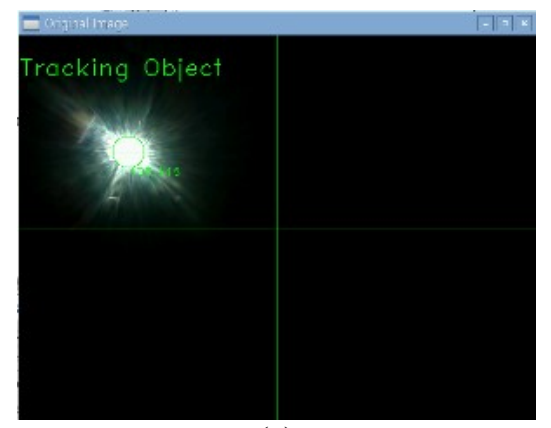

(a)

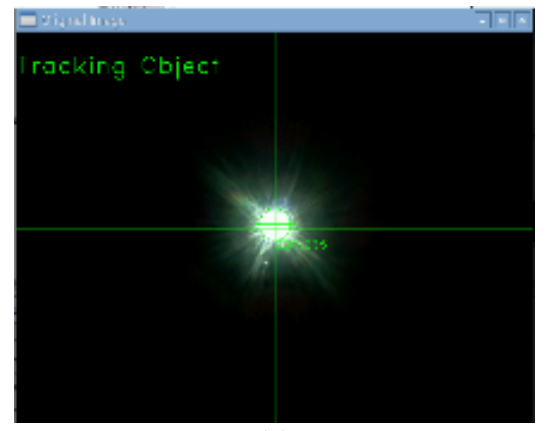

(c)

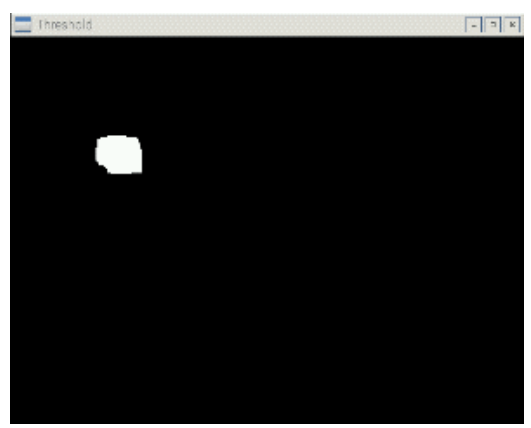

(b)

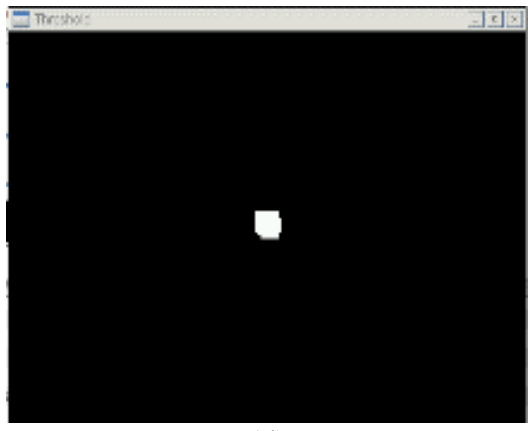

(d)

Gambar 12. Snapshot pergerakan panel surya: (a) posisi awal titik cahaya, (b) hasil pengolahan citra, (c) tampilan kamera setelah digerakan oleh linier aktuator, (d) posisi terakhir hasil pengolahan citra

Pengujian pertama adalah pendeteksian posisi titik cahaya. Pada Gambar 12 (a), titik cahaya terdeteksi berada pada kiri atas kamera atau berada pada kuadran 2. Gambar 12 (b) adalah hasil dari setelah pengaturan nilai HSV dan penentuan kontur dan momen. Dari proses ini didapatkan titik cahaya berada pada $\mathrm{x}=139$ dan $\mathrm{y}=113$. Agar permukaan panel surya dapat tersinari semua, maka titik cahaya tersebut harus berpindah menuju titik tengah kamera.

Pengujian selanjutnya adalah menggeser posisi titik cahaya pada kuadran 2 menuju ke tengah kamera. Pergeseran ini menggerakan dua buah linier aktuator menuju titik yang diinginkan, yaitu $\mathrm{x}=$ 240 dan y $=320$ dengan algortima yang telah dibahas pada pembahasan sub-bab 2.3. Gambar 12 (c) menunjukan titik cahaya telah berhasil berada posisi tengah kamera dengan menggerakan dua buah linier aktuator dan Gambar 12 (d) merupakan hasil akhir pendeteksian posisi cahaya. 


\section{KESIMPULAN}

Sistem penjejak matahari telah berhasil dirancang dan diimplementasikan dimana meliputi perancangan sistem, pembuatan rangka, pembuatan sistem elektrik, serta pengolahan citra untuk mendeteksi cahaya matahari. Hasil pengujian menunjukan sistem penjejak matahari telah berhasil mendeteksi posisi cahaya, kemudian rangka penjejak sinar matahari telah berhasil menggerakan dua buah linier aktuator menuju posisi yang diinginkan, yaitu berada pada titik tengah kamera. Dengan demikian, secara eksperimental permukaan panel surya dapat sepenuhnya tersinari cahaya. Untuk selanjutnya, terdapat beberapa pengembangan dapat dilakukan, yaitu efisiensi energi yang diperlukan untuk sistem elektrik dan pemrosesan gambar, menggunakan beberapa algoritma supaya dapat memperkaya sistem penjejak matahari, dan melakukan peningkatan efisiensi panel surya supaya energi matahari dapat terserap maksimal dengan berbagai metode.

\section{UCAPAN TERIMA KASIH}

Ucapan terima kasih penulis sampaikan kepada Lembaga Penelitian dan Pengabdian Masyarakat (LPPM) Universitas Katolik Parahyangan (UNPAR) sebagai kontributor utama dalam pembuatan penjejak matahari ini dan Laboratorium Elektronika di Jurusan Teknik Elektro Konsentrasi Mekatronika UNPAR

\section{REFERENSI}

[1] M. S. Boedoyo, "Potensi Dan Peranan Plts Sebagai Energi Alternatif Masa Depan Di Indonesia," J. Sains dan Teknol. Indones., vol. 14, no. 2, pp. 146-152, 2013.

[2] B. H. Purwoto, "Efisiensi Penggunaan Panel Surya Sebagai Sumber Energi Alternatif," Emit. J. Tek. Elektro, vol. 18, no. 01, pp. 10-14, 2018.

[3] A. Julisman, I. D. Sara, and R. H. Siregar, "Prototipe Pemanfaatan Panel Surya Sebagai Sumber Energi Pada Sistem Otomasi Stadion Bola,” J. Karya Ilm. Tek. Elektro, vol. 2, no. 1, pp. 35-42, 2017.

[4] Safrizal, "RANCANGAN PANEL SURYA SEBAGAI SUMBER ENERGI LISTRIK Jurnal DISPROTEK," J. Disprotek, vol. 8, no. 2, pp. 75-81, 2017.

[5] S. Bahari, A. Laka, and Rosmiati, "Pengaruh Perubahan Arah Sudut Sel Surya Menggunakan Energi Matahari Intensitas Cahaya Terhadap Tegangan," Semnastek 2017, November 2017, pp. 1-8.

[6] A. A. Smirnov, A. G. Vozmilov, and P. A. Romanov, "Comparison of discrete sun tracking methods for photovoltaic panels,” 2019 Int. Conf. Ind. Eng. Appl. Manuf. ICIEAM 2019, 2019, pp. 1-5.

[7] D. E. Myori, R. Mukhaiyar, and E. Fitri, "Sistem Tracking Cahaya Matahari pada Photovoltaic," INVOTEK J. Inov. Vokasional dan Teknol., vol. 19, no. 1, pp. 9-16, 2019..

[8] M. Mairizwan and H. Hendro, "Perancangan dan Pembuatan Prototype Sistem Tracker Sel Surya untuk Mengikuti Arah Gerak Matahari Berbasis Mikrokontroler Atmega328,” SNIPS 2015, 2015, pp. 101-104.

[9] K. K. Chong and C. W. Wong, "Open-loop azimuth-elevation sun-tracking system using on-axis general sun-tracking formula for achieving tracking accuracy of below 1 mrad," Conf. Rec. IEEE Photovolt. Spec. Conf., pp. 3019-3024, 2010.

[10] M. Romero, R. Lemuz, I. O. Ayaquica-Martínez, and G. Saldaña-Gonzílez, "A calibration algorithm for solar tracking system," Proc. - 2011 10th Mex. Int. Conf. Artif. Intell. Adv. Artif. Intell. Appl. MICAI 2011 Proc. Spec. Sess., pp. 139-143, 2011. 